\title{
Synchronous Versus Asynchronous: Pre-Service Teachers' Performance in Science Formative Assessment Tests
}

\author{
Philip Dorsah, Abdul-Ganiu Alhassan \\ Department of Science, Gambaga College of Education, Gambaga, Ghana \\ Email: pdorsah@gmail.com, alhassanganiyu@gmail.com
}

How to cite this paper: Dorsah, P. and Alhassan, A.-G. (2021) Synchronous Versus Asynchronous: Pre-Service Teachers' Performance in Science Formative Assessment Tests. Open Access Library Journal, 8: e7193 https://doi.org/10.4236/oalib.1107193

Received: January 27, 2021

Accepted: April 23, 2021

Published: April 26, 2021

Copyright $\odot 2021$ by author(s) and Open Access Library Inc.

This work is licensed under the Creative Commons Attribution International License (CC BY 4.0).

http://creativecommons.org/licenses/by/4.0/

\section{(c) (i) Open Access}

\begin{abstract}
The purpose of the study was to assess the performance of pre-service teachers in three science formative assessment tests in an online learning environment. The participants consisted of 138 pre-service teachers (57 participated in synchronous session and 81 participated in asynchronous sessions). The study used a quasi-experimental design, non-equivalent groups post-test only. Tests were used to collect the data: Energy Concept Test (ECT), Teaching Energy Concept Test (TECT) and Basic Electronics Concept Test (BECT). ANOVA results revealed a significant effect of type of test on test scores of students at the $p<0.05$ level for the three tests $[F(2,364)=9.641, p=0.000]$. For the ECT, there was no significant difference in performance between synchronous group $(M=15.93, S D=3.098)$ and asynchronous group $(M=$ $14.75, S D=3.691), t(1.791) p=0.076$. For the TECT, there was no significant difference in performance between synchronous group $(M=13.55, S D=$ 4.069) and asynchronous group $(M=13.97, S D=3.312), \mathrm{t}(-0.596) p=0.553$. Also, for the BECT, there was no significant difference between synchronous group $(\mathrm{M}=16.53, S D=2.727)$ and asynchronous group $(\mathrm{M}=15.19, \mathrm{SD}=$ 3.725), $t(2.287) p=0.024$. Pre-service teachers' performance in the three tests was higher than average. Online learning is an effective medium for teaching and learning of science and can be analogous to face-to-face instruction. Both synchronous and asynchronous environments prove effective for teaching and learning science.
\end{abstract}

\section{Subject Areas}

Science Education, Online Learning

\section{Keywords}

Online Learning, Synchronous, Asynchronous, Pre-Service Teachers, 
Science Instruction

\section{Introduction}

The global higher education landscape has dramatically changed due to the spread of the coronavirus, otherwise known as COVID-19 [1]. According to [2], the coronavirus pandemic is a typical adaptive and transformative challenge for educators and that education leaders must swiftly design responses as the pandemic runs its course. Many governments are implementing measures that limit the number of people congregating in public places. Such measures have disrupted the normal functioning of schools and universities [2].

While school closures seem to present a logical solution to enforcing social distancing within communities, prolonged closures tend to have a disproportionately negative impact on the most vulnerable students [3]. Many countries have turned to distance learning as a means of mitigating for lost time in school [3]. As a result, tertiary institutions in Ghana have adopted online teachings to enable students learn whiles they stay at home. According to [4], online learning is education in which instruction and content are delivered primarily over the Internet. Reference [5] found that online education is variously termed from the literature as "distance education," "e-learning," "online learning," "blended learning," "computer-based learning," "web-based learning," "virtual learning," "tele-education," "cyber learning," "Internet-based learning," and "distributed learning". Paulsen presented the following characteristics of online education as cited in [6]:

1) The separation of teachers and learners which distinguishes it from face-to-face education;

2) The influence of an educational organization which distinguishes it from self-study and private tutoring;

3) The use of a computer network to present or distribute some educational content;

4) The provision of two-way communication via a computer network so that students may benefit from communication with each other, teachers, and staff.

E-learning can and should significantly enhance science teaching and learning and may be used in a blended and coherent fashion to extend onsite learning experiences [7]. Reference [8] cited Koohang \& Harman that e-learning is the provision of educational activities related to teaching, learning and knowledge via electronic media. Similarly, [9] presented the concept of e-learning as online education, defined by the provision of training at its own pace or in real time, via the internet, to a device possessed by users. Online teaching and learning can contribute to a good learning science environment and can bring about good science education standards through proper designing and effective utilization of technology [10]. 
In online education, learning is either asynchronous or synchronous or a combination of both. Asynchronous learning is teaching and learning that do not happen at the same time [11], while synchronous learning refers to teaching and learning that happen at the same time, both of which are conducted through technologies such as Internet [5]. According to International Association for K-12 Online Learning [12], Synchronous learning is online learning in which the participants interact at the same time and in the same space. Asynchronous learning is defined as communication exchanges which occur in elapsed time between two or more people [12]. The appropriate mode of online teaching (i.e. whether synchronous or asynchronous) has been the question for many educators. Researchers have tried to determine the media that work best [13]. The rest of this paper is organized as follows: Section 2 presents a review of literature on synchronous and asynchronous online learning; Section 3 is the design of the study, data collection procedure and instruments; Section 4 presents the results of the study; Section 5 is discussion; and Section 6 is conclusion.

\subsection{Problem Statement}

It has been observed that students face diverse challenges with the emergency remote learning, especially students in remote villages and towns where there is no access to internet connectivity. These students had to participate asynchronously in online learning at their own time and pace.

What will be the performance of students in science assessment tests in an online environment? Which online learning mode should teachers and educators adopt for emergency remote learning? A review of literature revealed a lot of research on students' and teachers' perceptions, motivations, and participation in synchronous and asynchronous online learning. However, the effect of synchronous and asynchronous participations on students' academic performance especially in science is limited. This study intended to determine the effect of synchronous and asynchronous participations on pre-service teachers' performance in three different online science formative assessment tests.

\subsection{Research Questions}

1) What is pre-service teacher's performance in online science formative tests in synchronous and asynchronous environments?

2) Is there any significant difference in performance of pre-service teachers in online science formative tests between synchronous and asynchronous participation?

\section{Literature Review}

E-learning is learning process created by combining digitally delivered content with learning support and services [7]. According to [7], E-learning can and should significantly enhance science teaching and learning and may be used in a blended and coherent fashion to extend onsite learning experiences. E-learning 
refers to the use of modern technology, such as computers, digital technology, networked digital devices (such as the Internet) and associated software and courseware to facilitate the learning process [14] [15].

One of the modes used in e-learning is synchronous learning, which can be online, real-time, live teacher instruction and feedback, Skype conversations, videoconferencing, chat rooms, and virtual classrooms where everyone is online and working collaboratively at the same time [15].

Online learning environments can be divided into a triad of synchronous, asynchronous and hybrid learning environments. Synchronous learning environments provide real time interaction, which can be collaborative in nature [16], such as an instructor's lecture with a facility of questions-answer session. Synchronous session requires student-teacher presence at the same time and is live, real-time (and usually scheduled), facilitated instruction and learning-oriented interaction [17].

Asynchronous environments are not time bound and students can work on e-tivities on their own pace [18]. Asynchronous mode of learning/teaching has been the most prevalent form of online teaching so far because of its flexible modus operandi [19]. Asynchronous environments provide students with readily available material in the form of audio/video lectures, handouts, articles and power point presentations. These materials are accessible anytime anywhere via Learning Management System (LMS) or other channels of the sort [18]. Asynchronous e-learning is the most adopted method for online education because learners are not time bound and can respond at their leisure [20]. Asynchronous e-learning can be challenging requires strategies to keep students engaged and interested [18]. Synchronous e-learning, on the other hand, refers to learning/teaching that takes place simultaneously via an electronic mode [21].

A synchronous virtual classroom is a place for instructors and students to interact and collaborate in real time. Synchronous learning involves the exchange of ideas and information with one or more participants during the same period [22]. Synchronous learning is described as learning that takes place simultaneously in real-time. Learners attend class at a scheduled time either in a traditional classroom or a course delivered via the web, using various technologies [23]. According to [24], synchronous learning facilitates efficient education and provides both students and teachers with various ways of networking and sharing and collaborating in real-time. E-learning involves asynchronous as well as synchronous modes of communication [19].

Asynchronous online learning is a situation where students interact with each other, over a time gap, with the help of tools such as discussion forums, e-mail, and bulletin boards [25]. Asynchronous communication better supports cognitive participation because of increased reflection and ability to exchange complex information [6]. Synchronous learning mode is more similar to traditional teaching because communication in this mode is carried out in real time [6]. Synchronous communication enables students to watch teachers' presentations and verbally interact with the teachers during learning sessions [26]. Because 
synchronous communication mode is carried out in real time, discussions become more dynamic compared to using solely asynchronous communication [27]. The emerging consensus regarding the choice of asynchronous and synchronous modes is that neither is inherently better, but that they complement one another [28].

According to [29], asynchronous communication is self-paced, thereby accommodating learning differences and allowing cognitive room for the careful construction and understanding of content. Reference [19] Asserted that synchronous mode is good for discussing less complex issues and planning tasks. Students are highly motivated to participate in synchronous discussions because responses happen rapidly [19].

\section{Design of the Study}

The study used a quasi-experimental design, non-equivalent groups post-test only design. One group consisted of students who participated in synchronous online science lectures real-time in a Google classroom. The second group consisted of students who participated in asynchronous online science lectures at their own time and pace in Google classroom platform. The second group did not come online for synchronous sessions, they followed discussions on the online platform's stream, download course materials, lecture notes, videos, presented assignments and quizzes at their own pace at different times. The researchers administered the same treatment (online lectures, discussions, chats) to both groups on the same platform. There was no pre-test. Both groups took the post tests at the same time, after completing each unit. The design of the study is illustrated in Table 1.

\subsection{Online Learning Platform}

Google classroom platform was created at the beginning of the semester in April 2020 and the unique class code given to students to join. By the end of the first week all the students had joined the class. Class tests were created using Google forms and the links shared to students in Google classroom. Google Classroom is a simplified learning management system that was launched by Google in 2014 [30]. Teachers have the ability to attach documents, video, links, and connect to documents in Google Drive. Google Classroom can be used for sharing of tasks, assignments submission as well as assessment and for collaboration [31].

According to [32], the Google classroom design simplifies the instructional interface and options used for delivering and tracking assignments. Reference [32] added that Google classroom is designed to save time in that it integrates and automates the use of other Google applications such as Google docs, slides, and spreadsheets. The process of grading, formative assessment, and feedback is also made simple. A screenshot of the Google classroom platform is shown in Figure 1. The main features of the screenshot are the stream tab, classwork tab, people tab, and grades tab. 


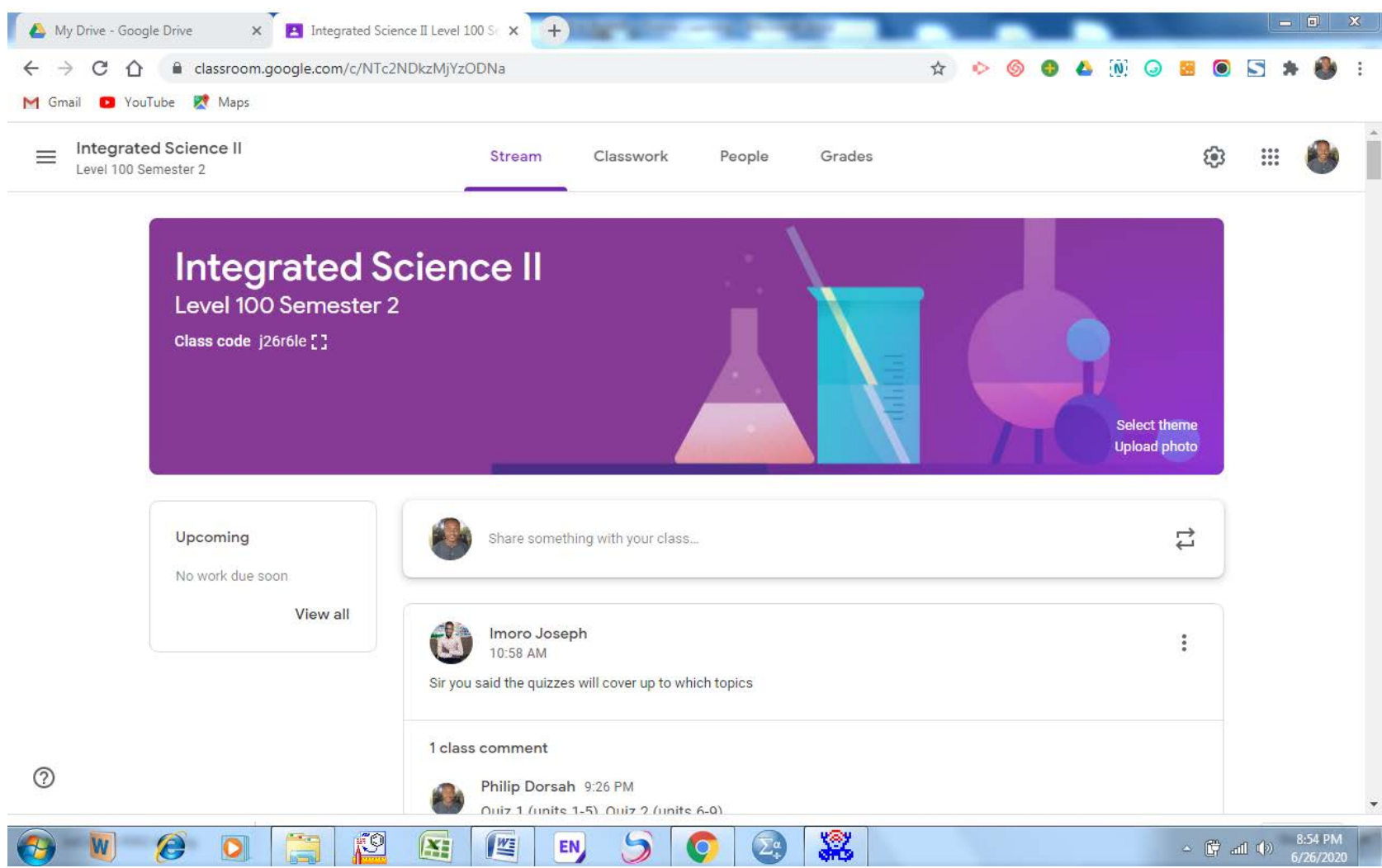

Figure 1. Screenshot of the Google classroom platform.

Table 1. Design of the study.

\begin{tabular}{ccc}
\hline Group & Intervention & Post-Test \\
\hline Synchronous & Online Instruction & ECT, TECT, BECT \\
Asynchronous & Online Instruction & ECT, TECT, BECT \\
\hline
\end{tabular}

- The Stream tab: is where teachers view and add announcements, assignments, discussion topics, and comments. Students can also view and access announcements, assignments, discussion topics, and comments.

- Classwork tab: Teachers can use this tab to create assignments and quizzes. Students can also see all of their assignments/work listed in chronological order based on the date assigned.

- People tab: Teachers can use this tab to add and remove co-teachers and students to the class. This tab also provides an easy way to email groups of students.

- Grade tab: After a student turns in work, the teacher can add comments, add a grade, and return the work.

\subsection{Data Collection Procedure}

Data collection process took six weeks. At the beginning of the semester, the course outline, course description and the assessment mode were provided for 
the students through the Google classroom platform. The treatment which was mainly online teaching, discussions, online activities, presentations, videos and chats were provided and facilitated by the researcher. The Google classroom platform gave students the opportunity to make comments, ask and respond to questions, post completed assignments and also download course materials. After every online teaching session, the researcher uploaded the lecture notes and other relevant materials on the platform for students to have access. The tests were conducted after completing each unit. Students were always pre-informed of the day and time of the test to enable them prepare adequately.

\subsection{Instruments}

The instruments for data collection were mainly tests: Energy Concept Test (ECT), Teaching Energy Concept Test (TECT) and Basic Electronics Concept Test (BECT). Each test consisted of 20 multiple choice question (MCQ) items including true or false items. The test items were carefully designed by the authors using the course content and other relevant reference materials. According to [33], Multiple Choice Question (MCQ) tests are one of the most widely used teaching tools, and has translated very successfully into the online environment. Again, [33] are of the view that MCQ quizzes have a role in terms of testing that students have grasped the key facts and ideas. MCQ questions can be used to cement students' understanding of the more subtle points in the lectures, particularly through the use of the carefully constructed feedback. The questions were carefully designed to address the educational objectives outlined in the course content. Students were given immediate feedback after submitting their answers and were also allowed to see their scores after submission. The tests were given to two colleagues to read through for corrections and to ensure content validity of test items. All tests were administered online in Google classroom platform. Each correct item in the test scored 1 point and an incorrect answer scored zero (no point). The total score for each of the three tests was 20 points. Students were allowed to see their scores immediately after submitting. Tests were taken at different times, a week after completing each unit. An example of sample item and sample answer with feedback is given in Figure 2 and Figure 3 respectively.

\subsection{Study Participants}

The participants consisted of 138 pre-service teachers (57 participated in synchronous session and 81 participated in asynchronous sessions). However, not all participants took the tests. This was due to challenges of internet connectivity and so it was not possible to get all students taking the tests.

For synchronous group, 44 students took the ECT (21 males, 23 females), 47 students took the TECT (19 males, 28 females) and 55 students took the BECT (21 males, 34 females). Also, for the asynchronous group, 75 students took the ECT (43 males, 32 females), 65 students took the TECT (40 males, 25 females) and 81students took the BECT (44 males, 37 females). 


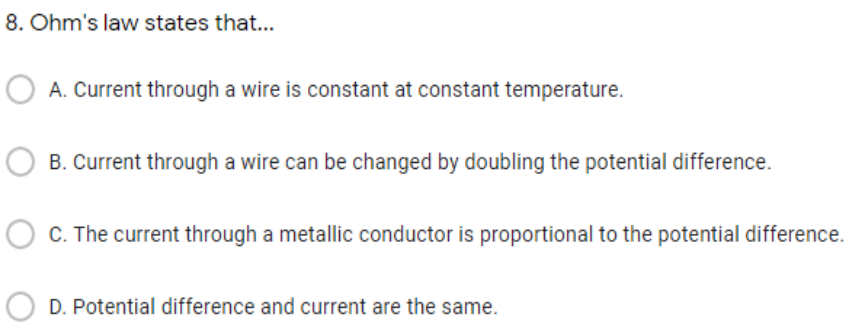

Figure 2. Screenshots of sample test item of the BECT.

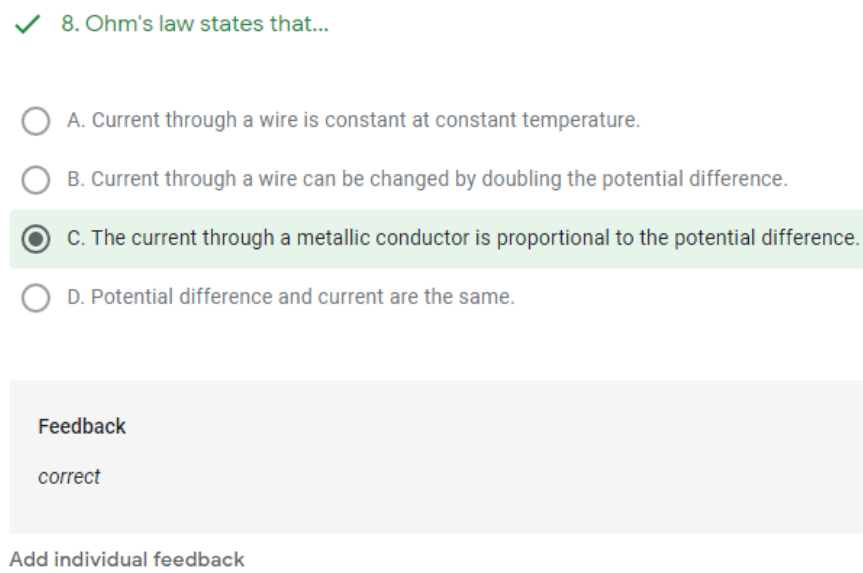

Figure 3. Screenshot of sample response with correct answer and feedback.

\section{Results}

\subsection{Research Question 1}

What is pre-service teacher's performance in online science formative tests in synchronous and asynchronous environments?

Table 2 shows the descriptive statistics of pre-service teachers' performance in the three tests for synchronous and asynchronous.

For the energy concept test (ECT), the mean score for synchronous group ( $M$ $=15.93, S D=3.09)$ and the mean score for asynchronous group $(M=14.75, S D$ = 3.691). For the teaching energy concept test (TECT), the mean score for synchronous group $(M=13.55, S D=4.069)$ and the mean score for asynchronous group $(M=13.97, S D=3.312)$. For the basic electronics concept test (BECT), the mean score for synchronous group $(M=16.53, S D=2.727)$ and the mean score for asynchronous group $(M=15.19, S D=3.725)$. In the ECT, the mean score for synchronous group is higher than asynchronous group. Synchronous group also obtained higher mean score than asynchronous group in the BECT. However for the TECT, the mean scores for the two groups were almost the same. It is evident from the results that, for both groups, pre-service teachers' 
performance in the TECT was low compared with their performance in the ECT and the BECT. It also emerged that in all, pre-service teachers performed better in the BECT than they performed in the ECT and the TECT.

ANOVA was performed to see if any significant difference exists in the performance of students in the three tests for both groups combined. Table 3 shows the results of the ANOVA.

The results revealed a significant effect of test type on test scores of students at the $p<0.05$ level for the three tests $[F(2,364)=9.641, p=0.000]$. Post hoc comparisons using the Tukey HSD test indicated that the mean score for the ECT $(M=15.18, S D=3.517)$ was significantly different than the TECT $(M=$ $13.79, S D=3.637)$. Also, the mean score for the BECT $(M=15.73, S D=3.41)$ was significantly different from the TECT ( $M=13.79, S D=3.637)$. However, the ECT scores did not significantly differ from the BECT scores.

\subsection{Research Question 2}

Is there any difference in performance in online science formative tests between synchronous and asynchronous participation?

Independent samples t-test was used to determine if there is any significant difference in the performance of students in the two groups $(\alpha=0.05)$ for the three tests. Table 4 shows the results of the independent samples t-test.

For the ECT, the results show that there was no significant difference in performance between synchronous group $(M=15.93, S D=3.098)$ and asynchronous group $(M=14.75, S D=3.691), t(1.791) p=0.076$. For the TECT, the results showed that there was no significant difference in performance between synchronous group $(M=13.55, S D=4.069)$ and asynchronous group $(M=13.97$, $S D=3.312), t(-0.596) p=0.553$. For the BECT, the results show that there was no significant difference in performance between synchronous group $(\mathrm{M}=$ $16.53, S D=2.727)$ and asynchronous group $(\mathrm{M}=15.19, \mathrm{SD}=3.725), t(2.287) p$ $=0.024$.

Table 2. Descriptive statistics of scores in the three tests for both groups.

\begin{tabular}{ccccc}
\hline Test & Environment & $\boldsymbol{N}$ & $\boldsymbol{M}$ & $\boldsymbol{S} \boldsymbol{D}$ \\
\hline ECT & synchronous & 44 & 15.93 & 3.0981 \\
& asynchronous & 75 & 14.76 & 4.069 \\
TECT & Total & 119 & 13.55 & 3.312 \\
& asynchronous & 47 & 13.97 & 2.727 \\
& Total & 65 & 16.53 & 3.725 \\
BECT & synchronous & 112 & 15.19 & \\
\hline
\end{tabular}


Table 3. Results of ANOVA of scores of the ECT, TECT and BECT.

\begin{tabular}{cccccc}
\hline & SS & df & MS & $F$ & Sig. \\
\hline Between Groups & 238.32 & 2 & 119.16 & 9.64 & $0.000^{* *}$ \\
Within Groups & 4499.14 & 364 & 12.36 & & \\
Total & 4737.46 & 366 & & & \\
\hline
\end{tabular}

${ }^{* *}$ significant, $p<0.05$.

Table 4. Independent samples t-test between groups of the ECT, TECT and BECT scores.

\begin{tabular}{ccccccc}
\hline Test & Group & $\boldsymbol{N}$ & $\boldsymbol{M}$ & $\boldsymbol{S D}$ & $\boldsymbol{t}$ & $\boldsymbol{p}$ \\
\hline \multirow{2}{*}{ ECT } & Synchronous & 44 & 15.93 & 3.098 & 1.791 & $0.076^{*}$ \\
& Asynchronous & 75 & 14.75 & 3.691 & & \\
\hline \multirow{2}{*}{ TECT } & Synchronous & 47 & 13.55 & 4.069 & -0.596 & $0.553^{*}$ \\
& Asynchronous & 65 & 13.97 & 3.312 & & \\
\hline \multirow{2}{*}{ BECT } & Synchronous & 47 & 16.53 & 2.727 & 2.287 & $0.024^{*}$ \\
& Asynchronous & 65 & 15.19 & 3.725 & & \\
\hline
\end{tabular}

${ }^{*}$ not significant, $p>0.05$.

\section{Discussion}

The performance of students in both synchronous and asynchronous environments was above average. This suggests that online-learning environments can be effective in supporting students learning of science just like the traditional face-to-face science classrooms. There was no significant difference in the performance of students in the synchronous group and those in the asynchronous group with respect to the energy concept test (ECT), teaching energy concept test (TECT) and basic electronics concept test (BECT).

However, [34] in a comparative study of synchronous and asynchronous instructional approaches found that students in the asynchronous group performed better in the achievement test than those in the synchronous group. Reference [34] revealed that the students in asynchronous group developed more interest in studying Electrical Engineering than the students in the synchronous group. Reference [35] found that both the synchronous and asynchronous environments were viable and that students should be given a choice of modes. Reference [36] however, concluded that asynchronous environment is a better system of e-learning because it supports interaction anywhere and anytime. Reference [37] also reported that in terms of achievement and attitude outcomes, asynchronous environments had more positive effects than synchronous ones.

Research examining student views on online learning environments suggest both synchronous and asynchronous environments have benefits [38]. In a study, [39] reported that students indicated they understood more and per- 
formed better when participating in synchronous environments. Again, [38] reported that students enjoy the flexibility and work at their own pace style provided in asynchronous environments. Asynchronous communication may induce increased cognitive effort since students have more time for reflection [6]. According to [6] "Synchronous communication may also induce increased motivation and decreased ambiguity because of possibilities for immediate feedback" (p. 45). Again, [6] found clarity of design, interaction with instructors, and active discussions among course participants as key factors of students' satisfaction and perceived learning. Synchronous sessions are a good way of reducing distance in distance education [40].

\section{Conclusions}

It emerged from the study that in general, pre-service teachers' performance in the three online assessment tests was higher than average. This implies that online learning can be an effective model for teaching and learning of science which can be comparable to the traditional face-to-face instruction. Also, synchronous and asynchronous environments are both effective in teaching science and thus educators and teachers may adopt any of the modes for online instruction. Instructors and teachers should ensure that whether synchronous or asynchronous mode, science lessons should be interactive and engaging enough. Research found that communication plays a key role in online learning, where emphasis is placed on student interactions within a group rather than an instructor-led learning experience.

The amount of interactivity in online discussions has been shown to correlate positively with performance on written assignments. Studies also show that online instructors' behaviors such as using humor to break the ice, providing and inviting feedback from students, and addressing students directly by name help to provide a presence that is positively associated with student learning and satisfaction. Social presence is a key component in online education, which is the ability of participants in a community of inquiry to feel that they are socially and emotionally "real" people through the medium of communication being used. Reference [12] identified, among others the following standards for quality online teaching:

1) Ability to construct flexible, digital, and interactive learning experiences that are useful in a variety of delivery modes.

2) ability to select and use a variety of online tools for communication, productivity, collaboration, analysis, presentation, research, and online content delivery as appropriate to the content area and student needs.

3) Ability to use student centered instructional strategies that are connected to real-world applications to engage students in learning (e.g., peer based learning, inquiry-based activities, collaborative learning, discussion groups, self-directed learning, case studies, small group work, and guided design).

4) Ability to apply strategies for engagement in online learning environments, 
e.g., asking questions to stimulate discussion.

5) Ability to provide prompt feedback, communicate high expectations, and respect diverse talents and learning styles.

6) Ability to develop and deliver assessments, projects, and assignments that meet standards-based learning goals and assess learning progress by measuring student achievement of learning goals.

7) Ability to create or select and implement a variety of formative and summative assessments that assess student learning progress and utilize student feedback to improve the online learning experience.

8) Ability to provide consistent feedback and course materials in a timely manner, and use online tool functionality to improve instructional efficiency.

9) Ability to track student enrollments, attendance records, etc.

\section{Limitations of the Study}

The main limitation of the study was internet connectivity challenges that students encountered. Due to poor or lack of internet connectivity, not all participants were able to take all the tests. Another limitation could come from the type of test items; one disadvantage of multiple choice tests is the limited types of knowledge that can be assessed.

\section{Conflicts of Interest}

The authors declare no conflicts of interest regarding the publication of this paper.

\section{References}

[1] Quacquarelli Symonds (2020) The Impact of the Coronavirus on Global Higher Education. Quacquarelli Symonds, London.

http://info.qs.com/rs/335-VIN-535/images/The-Impact-of-the-Coronavirus-on-Glo bal-Higher-Education.pdf

[2] Reimers, F., Schleicher, A., Saavedra, J. and Tuominen, S. (2020) Supporting the Continuation of Teaching and Learning during the COVID-19 Pandemic-Annotated Resources for Online Learning. Organisation for Economic Co-Operation and Development, Paris. https://www.oecd.org/education/Supporting-the-continuation-of-teaching-and-lear ning-during-the-COVID-19-pandemic.pdf

[3] Azzi-Huck, K. and Shmis, T. (2020) Managing the Impact of COVID-19 on Education Systems around the World: How Countries Are Preparing, Coping, and Planning for Recovery.

https://blogs.worldbank.org/education/managing-impact-covid-19-education-syste ms-around-world-how-countries-are-preparing

[4] Watson, J.F. and Kalmon, S. (2005) Keeping Pace with K-12 Online Learning: A Review of State-Level Policy and Practice. Learning Point Associates, Naperville. http://www.learningpt.org/pdfs/tech/Keeping_Pace2.pdf

[5] Sun, A. and Chen, X. (2016) Online Education and Its Effective Practice: A Research Review. Journal of Information Technology Education: Research, 15, 157-190. http://www.informingscience.org/Publications/3502 
https://doi.org/10.28945/3502

[6] Hrastinski, S. (2007) Participating in Synchronous Online Education. KFS AB, Sweden.

[7] National Science Teaching Association (2016) The Role of E-Learning in Science Education. NSTA Position Statement. http://www.nsta.org/about/positions

[8] Sangrà, A., Vlachopoulos, D., Cabrera, N. and Bravo, S. (2011) Towards an Inclusive Definition of E-Learning. eLearn Center, Open University of Catalonia, Barcelona.

[9] Lee, T. and Lee, J. (2006) Quality Assurance of Web Based E-Learning for Statistical Education. In: Rizzi, A. and Vichi, M., Eds., Compstat 2006-Proceedings in Computational Statistics, Physica-Verlag HD, Heidelberg, 429-438.

https://doi.org/10.1007/978-3-7908-1709-6_34

[10] Deshmukh, V. and Sufian Forawi, A.J. (2012) The Role of E-Learning in Science Education Vis-A-Vis Teacher Training Institutes in Middle East. US-China Education Review A, 2, 142-148.

[11] Moore, M. and Kearsley, G. (2012) Distance Education: A Systems View of Online Learning. 3rd Edition, Wadsworth, Belmont.

[12] International Association for K-12 Online Learning (2011) The Online Learning Definitions Project. International Association for K-12 Online Learning (iNACOL), Vienna.

[13] Ross, S.M. and Morrison. G.R. (2004) Experimental Research Methods. In: Jonassen, D.J., Ed., Handbook of Research on Educational Communications and Technology, 2nd Edition, Lawrence Erlbaum Associates, Mahwah, 1021-1043.

[14] Clover, I. (2017) Advantages and Disadvantages of eLearning. https://elearningindustry.com/advantages-and-disadvantages-of-elearning

[15] Food and Agriculture Organization of the United Nations (FAO) (2011) E-Learning Methodologies: A Guide for Designing and Developing E-Learning Courses. Food and Agriculture Organization of the United Nations, Rome.

[16] Salmon, G. (2013) E-tivities: The Key to Active Online Learning. 2nd Edition, Routledge, London, New York. https://doi.org/10.4324/9780203074640

[17] Hyder, K., Kwinn, A., Miazga, R. and Murray, M. (2007) The eLearning Guild's Handbook on Synchronous E-Learning. The eLearning Guild, Santa Rosa.

[18] Perveen, A. (2016) Synchronous and Asynchronous E-Language Learning: A Case Study of Virtual University of Pakistan. Open Praxis, 8, 21-39.

[19] Hrastinski, S. (2008) Asynchronous \& Synchronous E-Learning. EDUCAUSE Quarterly, 31, 51-55.

[20] Parsad, B. and Lewis, L. (2008) Distance Education at Degree-Granting Postsecondary Institutions: 2006-07 (NCES 2009-044). National Center for Education Statistics, Institute of Education Sciences, U.S. Department of Education, Washington DC. https://nces.ed.gov/pubs2009/2009044.pdf

[21] Teng, D.C.E., Chen, N.S., Kinshuk and Leo, T. (2012) Exploring Students' Learning Experience in an International Online Research Seminar in the Synchronous Cyber Classroom. Computers \& Education, 58, 918-930.

[22] Eminue, U. O., Garba, A. and Njoku, C. I. (2020) Adoption of Synchronous Instructional Strategies and Students' Academic Performance in Accounting in Secondary Schools in Akwa Ibom State, Nigeria. European Journal of Education Studies, 7, 265-276.

[23] LeShea, A.V. (2013) The Effects of Synchronous Class Sessions on Students' Aca- 
demic Achievement and Levels of Satisfaction in an Online Introduction to Computers Course. Unpublished PhD Thesis, Lanier Technical College Faculty, Liberty University, Lynchburg.

[24] Higley, M. (2013) Benefits of Synchronous and Asynchronous E-Learning. https://elearningindustry.com/benefits-of-synchronous-and-asynchronous-e-learni $\underline{\mathrm{ng}}$

[25] Oye, N.D., Salleh, M. and Iahad, N.A. (2012) E-Learning Methodologies and Tools. International Journal of Advanced Computer Science and Applications, 3, 48-52. https://doi.org/10.14569/IJACSA.2012.030208

[26] Holmström, T. and Pitkänen, J. (2012) E-Learning in Higher Education. A Qualitative Field Study Examining Bolivian Teachers' Beliefs about E-Learning in Higher Education. Department of Education, Umeå University, Umeå.

[27] Niehues, J. (2007) The Use of (a) Synchronous Communication Tools in E-Learning. GRIN Verlag, Munich. https://www.grin.com/document/52285

[28] Hewett, B.L. (2006) Synchronous Online Conference-Based Instruction: A Study of Whiteboard Interactions and Student Writing. Computers and Composition, 23, 4-31.

[29] Mick, C.S. and Middlebrook, G. (2015) Asynchronous and Synchronous Modalities. In: Hewett, B.L. and DePew, K.E., Eds., Foundational Practices of Online Writing Instruction, The WAC Clearinghouse; Parlor Press, Anderson, 129-147. http://uilis.unsyiah.ac.id/oer/files/original/cd4504c30ba79174ce3ce69df1d110f2.pdf

[30] Izenstark, A. and Leahy, K. L. (2015) Google Classroom for Librarians: Features and Opportunities. Library Hi Tech News, 32, 1-3. https://doi.org/10.1108/LHTN-05-2015-0039

[31] Alim, N., Linda, W., Gunawan, F. and Md Saad, M.S. (2019) The Effectiveness of Google Classroom as an Instructional Media: A Case of State Islamic Institute of Kendari, Indonesia. Humanities \& Social Sciences Reviews, 7, 240-246.

[32] Janzen, M. (2014) Hot Team: Google Classroom. The Pennsylvania State University, State College.

[33] Clarke, S., Lindsay, K., McKenna, C. and New, S. (2016) INQUIRE: A Case Study in Evaluating the Potential of Online MCQ Tests in a Discursive Subject. Research in Learning Technology, 12, 249-260. https://doi.org/10.3402/rlt.v12i3.11257

[34] Raymond, E., Atsumbe, B., Okwori, R. and Jebba, A.M. (2016) Comparative Effects of the Synchronous and the Asynchronous Instructional Approaches Concerning the Students' Achievements and Interests in Electrical Engineering at the Niger State College of Education. International Journal of Engineering Pedagogy, 6, 4-9. https://doi.org/10.3991/ijep.v6i3.5302

[35] Davidson-Shivers, G., Muilenburg, L. and Tanner, E. (2001) How Do Students Participate in Synchronous and Asynchronous Online Discussions? Journal of Educational Computing Research, 25, 351-366. https://doi.org/10.2190/6DCH-BEN3-V7CF-QK47

[36] Chauhan, V. (2017) Synchronous and Asynchronous Learning. Imperial Journal of Interdisciplinary Research, 3, 1345-1348.

[37] Bernard, R. M., Abrami, P.C., Lou, Y., Borokhovski, E., Wade, A., Wozney, L., et al. (2004) How Does Distance Education Compare with Classroom Instruction? A Metaanalysis of the Empirical Literature. Review of Educational Research, 3, 379-439. https://doi.org/10.3102/00346543074003379

[38] Coogle, C. and Floyd, K. (2015) Synchronous and Asynchronous Learning Envi- 
ronments of Rural Graduate Early Childhood Special Educators Utilizing Wimba ${ }^{\circ}$ and Ecampus. MERLOT Journal of Online Learning and Teaching, 11, 173-187.

[39] Ward, M., Peters, G. and Shelley, K. (2010) Student and Faculty Perceptions of the Quality of Online Learning Experiences. International Review of Research in Open and Distance Learning, 11, 57-77. https://doi.org/10.19173/irrodl.v11i3.867

[40] McBrien, J. L., Cheng, R. and Jones, P. (2009) Virtual Spaces: Employing a Synchronous Online Classroom to Facilitate Student Engagement in Online Learning. The International Review of Research in Open and Distributed Learning, 10, 1-17. https://doi.org/10.19173/irrodl.v10i3.605 